\title{
Mental health of adolescent school children in Sri Lanka - a national survey
}

\author{
H Perera ${ }^{1}$ \\ Sri Lanka Journal of Child Health, 2004; 33: 78-81
}

(Key words: Adolescence, epidemiology, mental health)

\begin{abstract}
Objectives To assess prevalence of mental health problems in adolescent school children and measure impact of such problems on their well-being.
\end{abstract}

Method Study group was randomly selected from 14 districts of 7 provinces. Participants completed validated self-assessment questionnaires, which assessed symptoms of mental health problems and their impact on emotional, educational and social functioning.

Results 2007 adolescents aged 13-18 years participated in study. $18.9 \%$ showed an abnormal range in emotional and behavioural parameters of assessment schedule. $12.6 \%$ reported a definite or severe impact of their difficulties. Most impact was felt in educational functioning $(15.5 \%)$ and peer relationships (12.4\%). Males had significantly higher prevalence for mental health problems compared to females.

Conclusions Prevalence of mental health problems among adolescents in Sri Lanka is similar to that reported elsewhere in the world. Knowledge gained can be utilized for providing school and community based preventive mental health services.

\section{Introduction}

World Health Organization (WHO) reports that 17$20 \%$ suffer from significant mental health problems but majority do not come to the attention of mental health services ${ }^{1,2}$. Surveys across cultures show that mental health problems in children and adolescents are more prevalent in developing countries ${ }^{3}$. These studies identified poverty and social deprivation as important aetiological factors. Current research support that stress, depression, anxiety and health concerns are recurrent themes of health issues in adolescents $^{3}$.

\footnotetext{
${ }^{1}$ Senior Lecturer, Department of Psychological Medicine, University of Colombo.
}

(Received on 9 February 2004)
In Sri Lanka, main causes of morbidity and mortality in 15-24 year age group are deliberate self-harm and suicide, self-inflicted injuries and poisoning ${ }^{4}$. In comparison, death due to respiratory disease, heart disease and malignancy are insignificant. Highest incidence of suicide, which is 60 per 100,000 in males and 40 per100,000 in females, is in the $15-24$ year age group. In 1996, 83.4\% of deaths in 15-24 year age group, compared to $51.5 \%$ for $25-49$ year age group, were due to injury and poisoning ${ }^{4}$. Though these statistics indicate need for provision of mental health care of adolescents, we have very little understanding of the extent and nature of their psychological vulnerabilities.

\section{Objectives}

The objectives of the study were twofold.

1. To assess prevalence of symptoms of mental health problems in adolescent school children.

2. To measure impact of the symptoms in respect of chronicity of problem, level of distress and the educational and social impairment.

\section{Method}

Study group was chosen from students attending Years 9, 10 and 11. Sample comprised 17 random clusters identified through multistage stratified sampling from 14 districts in 7 provinces in the country. Northern and Eastern provinces were left out due to difficulties anticipated in accessing and conducting the study in those areas. However, from available figures for distribution of population from the national census of 2001 , it can be estimated that study sample represented $86.9 \%$ of the population in Sri Lanka ${ }^{5}$. Thus, the study sample could be considered a national sample. From each province, representative samples were calculated from randomly selected schools. The target group was 1317 year old children attending school. Hence, only schools with secondary education were included in sampling process. A list of schools in each chosen district with the number of adolescents in Years 9, 10 
and 11 were obtained from the Department of Education.

Participants completed a self-assessment questionnaire, viz. the Strength and Difficulties Questionnaire (SDQ). Participation by subjects was voluntary and anonymous. SDQ is a brief behavioural screening questionnaire with 4 symptom scales of 5 items each. The 4 scales and attributes they identify are as follows:

- Conduct problems - antisocial behaviour, defiance, irritability, aggression.

- Inattention and hyperactivity - restlessness, distractibility, inattention, impulsiveness.

- Emotional symptoms - unhappiness, fears, somatic symptoms, low confidence, low self esteem.

- $\quad$ Peer problems - low social relatedness.

SDQ identifies symptom scores as those in the "normal", "borderline" and "abnormal" ranges. Scores in all 3 ranges are provided in the 4 symptom scales and collectively as total difficulties score (TDS). In addition, there is an impact questionnaire, which assesses whether the adolescent thinks there is an emotional or behavioural problem and if so, the chronicity, distress, and social impairments ${ }^{6}$. The extent of distress, social impairments and burden to others are indicated as "only a little", "quite a lot", and "a great deal", which represent mild, moderate and severe respectively.

\section{Validation of SDQ in Sri Lanka}

The Sinhala translation of SDQ validated ${ }^{7}$ using both high risk and low risk populations of children and adolescents for mental health problems. The discriminant validity obtained using TDS is as follows:

Clinical population $(n=57)-$ Mean score 17.9

General population $(n=495)$ - Mean score 9.1

High predictive validity of SDQ is reported from studies in other developing countries in adolescents both in urban and rural settings and living under different socio-economic circumstances ${ }^{8,9}$. In addition, test retest reliability in clinic samples is $>95 \%$.

\section{Results}

Data of 2007 adolescent school children were available for analysis. 41 had not indicated age and gender but were included in analysis. Age distribution was 13-18 years with a mean age of 15.07 years. $57.3 \%$ were female. Females were in the majority in all age groups.

\section{Analysis of $S D Q$ scores}

"Borderline" and "abnormal" scores were obtained by $252(12.6 \%)$ and $126(6.3 \%)$ of sample respectively. Altogether, unhealthy scores were obtained by 379 (18.9\%) of sample. Table I gives the frequency distribution of individual symptom scores.

\section{Table 1}

Frequency distribution of individual symptom scores

$\begin{array}{lccc}\text { Symptom } & \text { Normal } & \text { Borderline } & \text { Abnormal } \\ \text { Conduct } & 1911 & 66 & 30 \\ \text { problem } & (95.2 \%) & (3.3 \%) & (1.5 \%) \\ & & & \\ \text { Hyperactivity } & 1078 & 393 & 496 \\ & (53.7 \%) & (19.6 \%) & (24.7 \%) \\ & & & \\ \text { Emotional } & 1736 & 146 & 136 \\ \text { difficulties } & (86.5 \%) & (7.3 \%) & (6.8 \%) \\ & & & \\ \text { Peer problems } & 1648 & 259 & 64 \\ & (82.1 \%) & (14.7 \%) & (3.2 \%)\end{array}$

Assessment of "caseness"

The "caseness" of individuals who reported symptoms is decided on basis of severity, persistence of symptoms or chronicity, level of distress, social impairments and burden on others. Only 38.8\% did not report any symptoms at all. $47.6 \%$ reported mild symptoms. $11.6 \%$ reported definite symptoms. 2.0\% reported severe symptoms. Thus, $13.6 \%$ were reporting symptoms that were intense in quality. $17.0 \%$ reported that symptoms had lasted over a year. $10.1 \%$ reported symptoms to have been present for $6-$ 12 months. $13.8 \%$ reported duration of $1-5$ months. Thus, for $27.1 \%$, symptoms were chronic. In addition, $2.9 \%$ and $9.8 \%$ reported that the symptoms caused severe and definite distress respectively.

\section{Impact on functioning}

Table 2 gives the frequency distribution of impact of symptoms on different areas of functioning in the 
individual. Most impact was felt in educational functioning (15.5\%) and peer relationships (12.4\%).

Table 2

\section{Frequency distribution of impact of symptoms on different areas of functioning}

$\begin{array}{lccc}\text { Area of life } & \begin{array}{c}\text { Only a } \\ \text { little }\end{array} & \begin{array}{c}\text { Quite a } \\ \text { lot }\end{array} & \begin{array}{c}\text { A great } \\ \text { deal }\end{array} \\ \text { Home life } & 526 & 120 & 48 \\ & (26.2 \%) & (6.0 \%) & (2.4 \%) \\ \text { Learning } & 455 & 195 & 116 \\ & (22.7 \%) & (9.7 \%) & (5.8 \%) \\ \text { Friendships } & 598 & 185 & 64 \\ & (29.8 \%) & (9.2 \%) & (3.2 \%) \\ \text { Leisure } & 453 & 126 & 64 \\ \text { activities } & (22.6 \%) & (6.3 \%) & (3.2 \%)\end{array}$

Table 3 gives frequency distribution of "borderline" and "abnormal" range symptoms scores according to age.

Table 3

Frequency distribution of 'borderline' and 'abnormal' range symptoms according to age

\begin{tabular}{|c|c|c|c|}
\hline $\begin{array}{c}\text { Age } \\
\text { (years) }\end{array}$ & $\begin{array}{c}\text { Borderline } \\
\text { score }\end{array}$ & $\begin{array}{c}\text { Abnormal } \\
\text { score }\end{array}$ & Total \\
\hline 13 & $\begin{array}{c}33 \\
(12.7 \%)\end{array}$ & $\begin{array}{c}14 \\
(5.4 \%)\end{array}$ & $\begin{array}{c}259 \\
(12.9 \%)\end{array}$ \\
\hline 14 & $\begin{array}{c}43 \\
(14.3 \%)\end{array}$ & $\begin{array}{c}24 \\
(8.0 \%)\end{array}$ & $\begin{array}{c}300 \\
(14.9 \%)\end{array}$ \\
\hline 15 & $\begin{array}{c}64 \\
(10.2 \%)\end{array}$ & $\begin{array}{c}28 \\
(4.5 \%)\end{array}$ & $\begin{array}{c}625 \\
(31.1 \%)\end{array}$ \\
\hline 16 & $\begin{array}{c}64 \\
(11.4 \%)\end{array}$ & $\begin{array}{c}47 \\
(8.4 \%)\end{array}$ & $\begin{array}{c}559 \\
(27.8 \%)\end{array}$ \\
\hline 17 & - & - & $\begin{array}{c}184 \\
(9.3 \%)\end{array}$ \\
\hline 18 & - & - & $\begin{array}{c}009 \\
(0.4 \%)\end{array}$ \\
\hline
\end{tabular}

Pearson chi square 152.5, df (degrees of freedom) $145, p>0.05$. There was no statistically significant association between age and total difficulties score in SDQ.
Table 4 gives frequency distribution of "borderline" and "abnormal" range symptoms scores according to gender.

\section{Table 4}

Frequency distribution of 'borderline' and 'abnormal' range symptoms according to gender

$\begin{array}{lccr}\text { Gender } & \begin{array}{c}\text { Borderline } \\ \text { score }\end{array} & \begin{array}{c}\text { Abnormal } \\ \text { scores }\end{array} & \text { Total } \\ \text { Female } & 137(11.9 \%) & 51(4.4 \%) & 1148 \\ \text { Male } & 109(13.3 \%) & 71(8.7 \%) & 818\end{array}$

Pearson chi square is 47.6 , df $29, \mathrm{p}<0.05$. The higher prevalence of symptoms in males was statistically significant.

Table 5 gives gender distribution of individual symptoms (borderline + abnormal scores).

Table 5

Gender distribution of individual symptoms (Borderline + abnormal scores)

\begin{tabular}{|c|c|c|c|c|c|}
\hline $\begin{array}{l}\text { Symptom } \\
\text { Scales }\end{array}$ & Female & Male & $\begin{array}{c}\text { Pearson } \\
\text { Chi } \\
\text { Square }\end{array}$ & $d f$ & $p$ \\
\hline $\begin{array}{l}\text { Hyperactivity } \\
\text { /inattention }\end{array}$ & $\begin{array}{l}476 \\
(41.3 \%)\end{array}$ & $\begin{array}{c}435 \\
(53.2 \%)\end{array}$ & 47.2 & 10 & $<0.05$ \\
\hline $\begin{array}{l}\text { Conduct } \\
\text { problems }\end{array}$ & $\begin{array}{c}30 \\
(2.6 \%)\end{array}$ & $\begin{array}{c}83 \\
(10.1 \%)\end{array}$ & 47.8 & 9 & $<0.05$ \\
\hline $\begin{array}{l}\text { Emotional } \\
\text { difficulties }\end{array}$ & $\begin{array}{c}164 \\
(14.2 \%)\end{array}$ & $\begin{array}{l}102 \\
(12.5 \%)\end{array}$ & 15.1 & 10 & $>0.05$ \\
\hline Peer problems & Is $\begin{array}{c}168 \\
(14.6 \%\end{array}$ & $\begin{array}{c}185 \\
(22.6 \%)\end{array}$ & 53.1 & 9 & $<0.05$ \\
\hline
\end{tabular}

There was a statistically significant higher prevalence of hyperactivity and inattention, conduct problem and peer problem scores in males. There is no significant difference in emotional difficulties scores between the males and females.

\section{Discussion}

Nearly 1 in 5 adolescents (18.9\%) in our schools appear to have clinically relevant mental health symptoms. In this respect, prevalence is similar to that documented elsewhere in the world. However, some epidemiological studies show that when severity of symptoms and need for treatment alone 
are considered, prevalence rate reduces to around $5 \%{ }^{10}$. Though a difference in this context is shown in our study too, prevalence still remains much higher with $13.6 \%$ reporting definite or severe symptoms and $12.7 \%$ reporting definite or severe distress. Thus, the numbers who may need professional help is more than double that reported elsewhere. Also, impact on education and peer relationships was higher than in other areas of life. This finding is compatible with the high levels of restlessness, impulsiveness poor concentration and irritability that were reported.

Some studies in Asia have found deterioration in mental health status in adolescents with increasing age $^{11}$. This is not apparent with our sample. However, when gender differences in symptom distribution are considered, boys show a significantly higher vulnerability than girls. This raises the question whether the negative consequence would be a higher dropout of boys early from schools. This is a justified concern especially in view of the skewed sex ratio found in the sample, when compared with the national figures of 97.7 males per 100 female $^{5}$.

There are some notable deficiencies in the study. Adolescents not attending schools may have a higher prevalence of mental health problems due to social reasons and educational failure, but were missed as study was restricted to schools. Also, the Tamilspeaking population was not included. In addition, useful information from teachers and parents could not be included, as participation by the subjects was kept anonymous.

\section{Clinical and service implications}

Results indicate that the health services should be concerned about the mental health needs of our adolescents and provide services at institutional and community level. In addition, educational services should focus on improving mental health literacy in school children and teachers, while taking measures to provide support and understanding to those in need.

\section{References}

1. World Health Organization. Mental Health Bulletin; 8 December 2000.

2. World Health Organization. Mental health: new understanding, new hope. World health report 2001; WHO, Geneva.

3. Hackett R, Hackett L. Child psychiatry across cultures. International Review of Psychiatry 1999; 11: $225-35$.

4. National Health Bulletin. Department of Health 1999, Sri Lanka.

5. 2001/2002 Sri Lanka population data sheet. Ministry of Health, Nutrition and Welfare, Sri Lanka.

6. Goodman R. Psychometric properties of the strengths and difficulties questionnaire. Journal of the American Academy of Child and Adolescent Psychiatry 2001; 40: 1337-45.

7. http://www.sdqinfo.com Accessed on 07/02/2004.

8. Fleitlich B, Goodman R. Social factors associated with child mental health problems in Brazil: cross sectional survey. British Medical Journal 2001; 323: 599-600.

9. Mullick M S, Goodman R. Questionnaire screening for mental health problems in Bangladeshi children: a preliminary study. Social Psychiatry and Psychiatric Epidemiology 2001; 36: 94-9.

10. Offord D R, Fleming J E. Epidemiology. In: Lewis M. editor. Child and Adolescent Psychiatry: a comprehensive textbook. Baltimore :Williams and Wilkins, 1996.

11. Wang X, Matsuda N, Ma H, Shinfuku N. Comparative study of quality of life between the Chinese and Japanese adolescent populations. Psychiatry and Clinical Neuro-sciences 2000; 54:147-52. 
